\title{
Isolation and Structure of an Extracellular Polysaccharide from Streptomyces sp. FERM-P1185
}

\author{
By T. MIYAZAKI AND H. YAMADA \\ Department of Microbial Chemistry, Tokyo College of Pharmacy, Hachiöji-shi, \\ Tokyo 192-03, Japan \\ J. AWAYA AND S. ŌMURA \\ Kitasato University and Kitasato Institute, Shirokane, Minato-ku, Tokyo 108
}

(Received 21 July 1975; revised 4 December 1975)

\begin{abstract}
SUMMARY
A streptomycete strain (FERM-PII85), isolated from soil, secreted a slime on glucose-asparagine agar, and produced viscous growth in liquid media containing peptone as nitrogen source. A purified polysaccharide isolated from the culture broth was composed of glucose and mannose units (molar ratio I $87: \mathrm{I}$ ). Periodate oxidation, Smith degradation, methylation analysis, infrared and ${ }^{13} \mathrm{C}$ nuclear magnetic resonance spectra, indicated that this mannoglucan had a linear structure consisting of $\alpha-1,3-$ and $\alpha-1,4$-linked glucopyranose and mannopyranose units.
\end{abstract}

\section{INTRODUCTION}

Much work has been done on extracellular polysaccharides produced by bacteria and fungi, but little attempt has been made to isolate these substances from streptomycetes. Recently, a Streptomyces sp. was isolated from soil, and found to produce an extracellular polysaccharide and a new antibiotic which inhibited plant pathogenic fungi, particularly Piricularia oryzae (Ōmura et al., 197I).

This paper describes the characterization of the strain, and the isolation and structural examination of the polysaccharide.

\section{METHODS}

Characterization and cultivation. The organism, strain FERM-PI I85, was described using the criteria applied in the International Streptomyces Project (Shirling \& Gottlieb, 1966) and identified on the basis of Bergey's Manual of Determinative Bacteriology (Pridham \& Tresner, 1974).

To produce the polysaccharide, an inoculum was pre-incubated in a medium containing $\left(\%\right.$, w/v): glycerol, I; starch, I ; soy bean meal, $2 ; \mathrm{CaCO}_{3}, 0.3$; and tap water, $\mathrm{pH} 7.0$; and shaken on a reciprocal shaker ( $120 \mathrm{rev} . / \mathrm{min})$ at $27^{\circ} \mathrm{C}$ for 2 days. The bacterial suspension was then transferred to the production medium containing $(\%, \mathrm{w} / \mathrm{v}):$ glucose, 6 ; peptone, $0.2 ; \mathrm{K}_{2} \mathrm{HPO}_{4}, 0 . \mathrm{I} ; \mathrm{MgSO}_{4} \cdot 7 \mathrm{H}_{2} \mathrm{O}, 0.05 ; \mathrm{CaCO}_{3}, 0.3$; and tap water, $\mathrm{pH} 7.0$; and shaken on a reciprocal shaker at $27{ }^{\circ} \mathrm{C}$ for 5 to 6 days.

Assay of mycelium growth. Broth culture ( $10 \mathrm{ml}$ ) was centrifuged for $\mathrm{I} 0 \mathrm{~min}$ at $800 \mathrm{~g}$ and the wet mycelium weighed.

Assay of residual glucose. The amount of glucose remaining in the culture medium was determined by the $o$-toluidine method (Dubowski, 1962). 
Analytical procedures. Ascending paper chromatography was performed using Toyo filter paper nos. 50 and 5I, and the solvent systems: ethyl acetate-pyridine-water (I0:4:3, by vol.), and ethyl acetate-pyridine-acetic acid-water $(5: 5: 1: 3$, by vol.). Sugars were detected with alkaline silver nitrate (Trevelyan, Procter \& Harrison, 1950) and $p$-anisidine hydrochloride (Hough, Jones \& Wadman, I950), and the total hexose content determined using phenol- $\mathrm{H}_{2} \mathrm{SO}_{4}$ (Dubois et al., I956). Evaporations were carried out in vacuo at under $35{ }^{\circ} \mathrm{C}$, and optical rotation determined at $22{ }^{\circ} \mathrm{C}$ using a Jasco (Tokyo, Japan) Dip-SL.

Gas-liquid chromatography (g.l.c.) was performed using a Shimadzu (Tokyo, Japan) GC-5A chromatograph with a glass column $(0.3 \mathrm{~cm} \times 200 \mathrm{~cm})$ and a gas flow rate of $50 \mathrm{ml}$ nitrogen $/ \mathrm{min}$. The column was packed with $5 \%$ (w/w) ECNSS-M (cyanoethylsilicone polymer) on Chromosorb W (aw-dmcs, 60 to 80 mesh) and operated at 170 to $180{ }^{\circ} \mathrm{C}$ for identification of the component sugars and the Smith degradation products: it was packed with $3 \%(\mathrm{w} / \mathrm{w})$ silicone OV-2 Io on Chromosorb W (aw-dmcs, 60 to 80 mesh) and operated at $170^{\circ} \mathrm{C}$ for identification of the $O$-acetyl- $O$-methyl alditols.

Mass spectra were recorded with a Hitachi RMU-7 $\mathrm{L}$ at $70 \mathrm{eV}$ ionization voltage. Infrared (i.r.) spectra were recorded with a Hitachi-2 I5 spectrometer; proton magnetic resonance spectra with a JNM-MH-Ioo spectrometer, using sodium 2,2,3,3-tetradeutro-3-(trimethylsilyl) propionate (TSP) as internal standard; and ${ }^{13} \mathrm{C}$ nuclear magnetic resonance spectra were measured at $25 \cdot \mathrm{I} \mathrm{MHz}$ with a JEOL PS-IOO spectrometer. All protons were decoupled. The polysaccharide was measured at a concentration in $\mathrm{D}_{2} \mathrm{O}$ of $80 \mathrm{mg} \mathrm{ml}^{-\mathbf{1}}$. Chemical shifts were measured using dioxane $[67 \cdot 4$ p.p.m. downfield from internal tetramethylsilane (TMS)] as an external standard, and were expressed relative to TMS. Spectra were determined after multiple scanning using a time-averaging device.

Chemicals. $\alpha$-Amylase was purchased from Seikagaku-kogyo Co. (Japan), and pronase from Kaken Kagaku Co. (Japan).

Isolation and purification of the polysaccharide. The mycelium and insoluble materials were removed by centrifuging and crude preparations of the polysaccharide precipitated from the culture filtrate by adding 2 vols. acetone. The precipitate was dehydrated with acetone and dried; the yield was about $9 \mathrm{~g} / \mathrm{ro}$ l culture broth.

The crude extracellular polysaccharide was dissolved in water and the solution adjusted to $\mathrm{pH} 7 \cdot 6$ with $\mathrm{NaHCO}_{3}$. Pronase was added, and the solution was incubated for 2 days at $37{ }^{\circ} \mathrm{C}$, and dialysed in Visking Cellophane tubing against running water for 2 days. The nondialysable portion was concentrated to a small volume, and freed from pronase by shaking with chloroform-butyl alcohol $(4: \mathrm{I}, \mathrm{v} / \mathrm{v})$ until no further gelatinous precipitate could be separated. After centrifuging, the aqueous solution was concentrated, and the product precipitated by addition of ethanol (yield was $13.6 \%$ of the pre-digested material).

\section{RESULTS}

\section{Characterization of the streptomycete strain}

The sporophores were located on short side branches on the flexuous main hyphae and terminated in closed to partly open spirals (Spirales) of two or more coils. The spores were oval or ellipsoidal $(0.5$ to $0.8 \mu \mathrm{m} \times \mathrm{I} \cdot 0$ to $1.5 \mu \mathrm{m})$ and had a smooth surface (Fig. I). There was no evidence of sporangia, zoospores or sclerotia. The cultural and physiological characteristics of the strain are summarized in Tables $\mathrm{I}$ and 2.

The strain was classified in the white series, Group W; S; C- ; SM (Pridham \& Tresner, 1974), was considered to be similar to Streptomyces rimosus (Sobin, Finlay \& Kane) Waksman (Waksman, 1953) and was assigned to the 'rimosus' subgroup. The properties of 


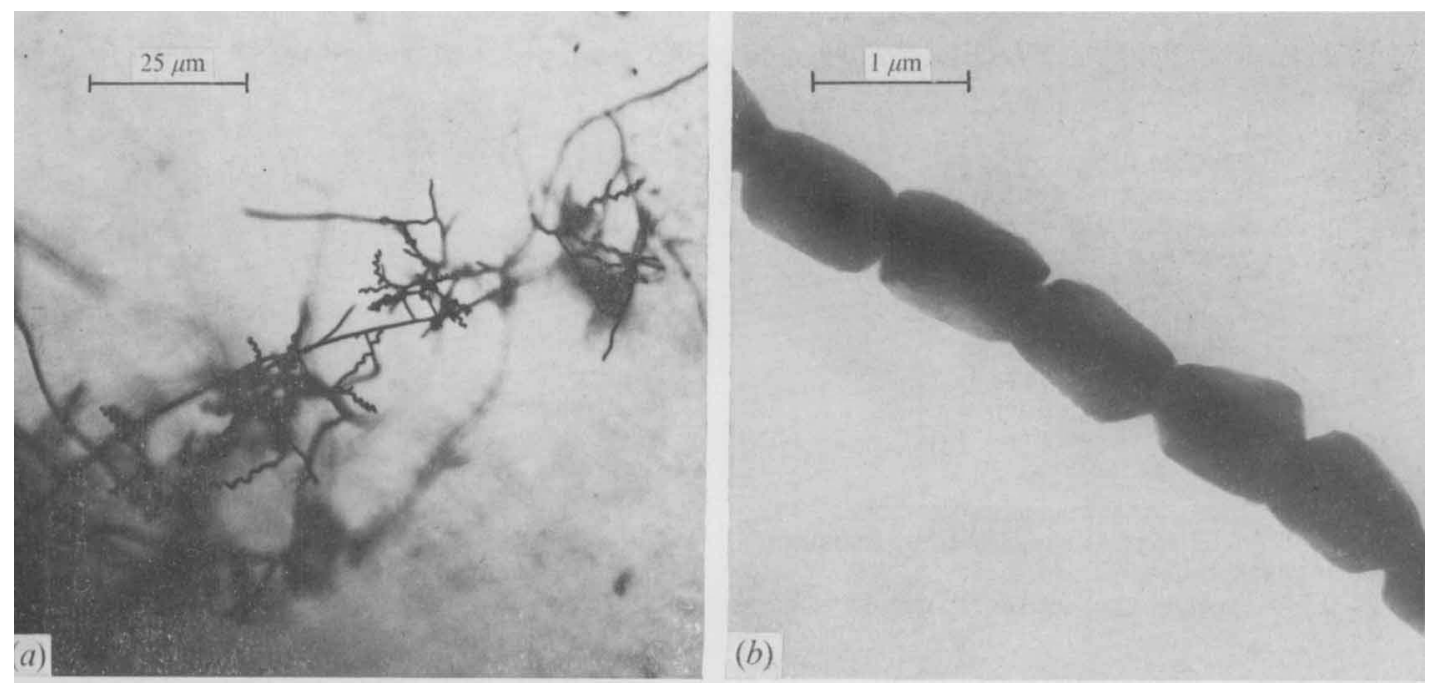

Fig. I. (a) Aerial mycelium and (b) spore chain morphology of Streptomyces sp. FERM-PI I 85 grown on oatmeal agar for 14 days at $27^{\circ} \mathrm{C}$.

Table I. Cultural characteristics of Streptomyces sp. FERM-PI I 85

\section{Medium}

Sucrose-nitrate agar

Glucose-asparagine agar

Glycerol-calcium malate agar

Inorganic salts-starch agar

Tyrosine agar

Nutrient agar

Yeast extract-malt extract agar

Oatmeal agar

Glucose-peptone-beef agar

Potato-glucose agar
Growth

Poor, colourless

Good, spreading, slimy cream

Moderate, raised, pale yellow

Restricted, spreading, colourless with light gold coloured centre

Moderate, spreading, cream to butter yellow

Moderate, cream

Good, raised, light ivory to old gold coloured centre

Restricted, spreading, colourless

Moderate, raised, light antique gold to light wheat

Good, raised, light ivory to melon yellow
Aerial Soluble mycelium pigment

\begin{tabular}{|c|c|}
\hline None & None \\
\hline None & None \\
\hline None & None \\
\hline None & None \\
\hline None & Light gold \\
\hline None & None \\
\hline $\begin{array}{l}\text { Thin, } \\
\text { light ivory }\end{array}$ & Light gold \\
\hline $\begin{array}{l}\text { Thin, } \\
\text { light ivory }\end{array}$ & None \\
\hline None & Melon yellow \\
\hline None & Pale yellow \\
\hline
\end{tabular}

the strain were in good agreement with those of the type strain, S. rimosus ISP5260, with respect to the following morphological and cultural characteristics: both formed light ivory coloured aerial hyphae on yeast extract-malt extract agar and on oatmeal agar; produced reddish growth on yeast extract-malt extract and inorganic salts-starch agars; and a soluble yellow pigment in glucose-peptone-beef and tyrosine agars. Strain FERM-PI I 85 produced a characteristic slime on glucose-asparagine agar but unlike $S$. rimosus ISP5260 it did not use arabinose or raffinose as sole sources of carbon and energy for growth. 
Table 2. Physiological properties of Streptomyces sp. FERM-PI I 85

Property

Melanin formation

Tyrosinase production

Degradation of starch

Hydrogen sulphide production

Nitrate reduction

Liquefaction of gelatin

Liquefaction of serum

Coagulation of milk

Peptonization of milk

Cellulolytic activity

Temperature range

Sugars as sole source of carbon Glucose, fructose, inositol, mannitol Xylose

Arabinose, sucrose, rhamnose, raffinose
Reaction

\author{
Negative \\ Negative \\ Negative \\ Negative \\ Doubtful \\ Positive \\ Negative \\ Positive (strong) \\ Positive (weak) \\ Negative \\ No growth below $5{ }^{\circ} \mathrm{C}$ or above $50^{\circ} \mathrm{C}$ \\ Good growth \\ Poor growth \\ No growth
}

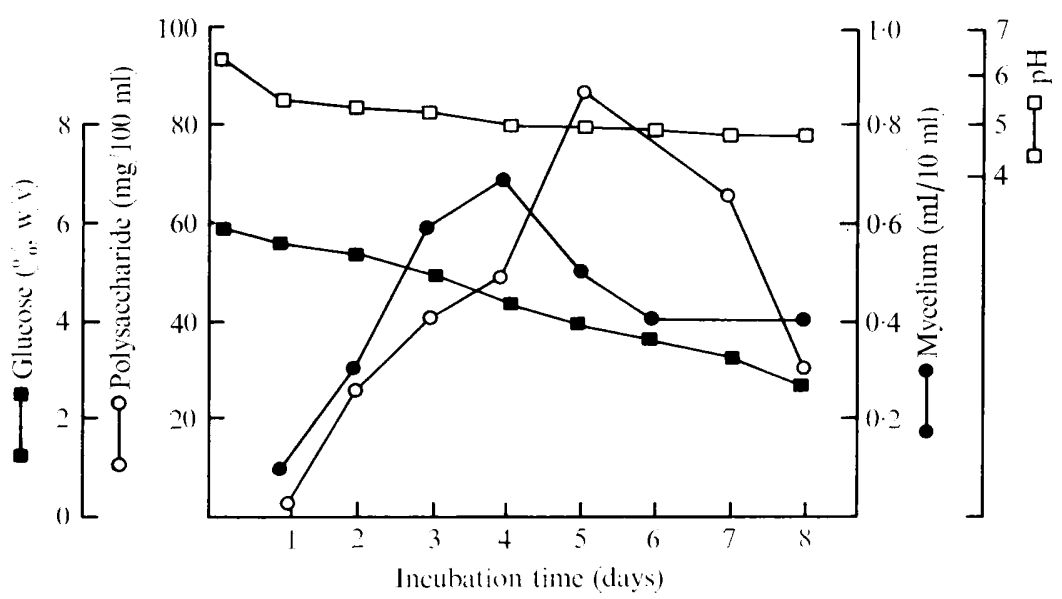

Fig. 2. Polysaccharide production by Streptomyces Sp. FERM-PI185. Changes in the residual glucose (D) and polysaccharide $(O)$ contents of the mycelium during its growth $(O)$ in broth culture. $\mathrm{pH}$ changes $(\square)$ during growth are also recorded.

\section{Production of the polysaccharide}

The most effective carbon and nitrogen sources for the production of the polysaccharide were glucose $(6 \%, w / v)$ and peptone $(0.2 \%, w / v)$. Maximum growth was achieved after 3 to 4 days, and the production of the polysaccharide increased with the viscosity of the broth culture reaching a maximum $(90 \mathrm{mg} / \mathrm{I} 00 \mathrm{ml})$ after 5 to 6 days (Fig. 2).

\section{Properties of the purified polysaccharide}

The purified polysaccharide (SM-P) gave a single spot on zone electrophoresis using Pevicon C-870 (polyvinyl resin, M \& S Instruments, Japan) and I \% borate buffer ( $\mathrm{pH} 9 \cdot 2$ ); and gave a single peak on gel filtration on a Sepharose-6B column. The polysaccharide was then considered to be pure enough for structural studies. Purified SM-P, $[\alpha]_{D}^{20}+\mathrm{I} 6 \cdot 2^{\circ}$ (c. 0.3 in water), did not give a blue colour with iodine, and contained $0.7 \%$ nitrogen and $95.4 \%$ total hexose. 


\title{
Table 3. Methyl ethers from the hydrolysate of the methylated polysaccharide
}

\begin{abstract}
Retention values of alditol acetate derivatives were measured by g.l.c. and are expressed relative to the mobility of 1,5 -di- $O$-acetyl-2,3,4,6-tetra- $O$-methyl-D-glucitol. Molar proportions of the methyl ethers were estimated from relative peak areas of the gas chromatogram.
\end{abstract}

Sugars

2,3,4,6-tetra- $O$-methyl hexose 2,4,6-tri- $O$-methyl hexose 2,3,6-tri-O-methyl hexose

$\begin{array}{cc}\begin{array}{c}\text { Relative } \\ \text { retention }\end{array} & \begin{array}{c}\text { Molar proportion } \\ (\%)\end{array} \\ 1 \cdot 00 & 2 \cdot 16 \\ I \cdot 78 & 50 \cdot 2 \\ 2 \cdot 23 & 47.6\end{array}$

Acid hydrolysis of the SM-P gave glucose and mannose in the molar ratio $\mathrm{I} \cdot 87: \mathrm{I}$. In its i.r. spectrum, the SM-P had an absorption maximum at $840 \mathrm{~cm}^{-1}$, which is characteristic of $\alpha$-glycosidic linkages (Barker et al., 1954). The proton magnetic resonance spectrum showed signals at $5 \cdot 16$ p.p.m., characteristic of an anomeric proton, but no signals of $O$-methyl, $O$-acetyl or other $O$-acyl groups. The SM-P did not react with $\alpha$-amylase of the saccharifying type from Bacillus subtilis.

\section{Periodate oxidation and Smith-type degradation}

Purified SM-P ( $12.5 \mathrm{mg}$ ) was dissolved in water ( $10 \mathrm{ml}$ ), the total volume made up to $25 \mathrm{ml}$ with $2 \mathrm{ml}$ of $0.22 \mathrm{M}$-sodium periodate in distilled water, and the reaction allowed to proceed in the dark at $25^{\circ} \mathrm{C}$ for $72 \mathrm{~h}$. The number of moles of sodium periodate reduced per anhydrohexose unit of the SM-P was 0.33 (after I h), $0.53(2 \mathrm{~h}), 0.54(3 \mathrm{~h}), 0.55(6 \mathrm{~h})$ and $0.55(24 \mathrm{~h}$ ), using the method of Malaprade (Hay, Lewis \& Smith, I965). No formic acid was detected (Whistler \& Hickson, 1954). The polyalcohol, obtained as a syrup after the addition of ethylene glycol $(0.5 \mathrm{ml})$, reduction with sodium borohydride $(7 \mathrm{mg})$ and dialysis followed by concentration, was hydrolysed with $0.25 \mathrm{M}$-sulphuric acid $(0.5 \mathrm{ml})$ for $5 \mathrm{~h}$ at $100{ }^{\circ} \mathrm{C}$. The degradation products in the solution were converted into their alditol acetate derivatives by reduction with sodium borohydride, followed by acetylation using acetic anhydridepyridine (I:I, v/v) (Sawardeker, Slonecker \& Jeanes, I965), and estimated by g.l.c. Molar ratios were calculated from the ratios of the areas under each peak in the chromatogram. Glucitol acetate, mannitol acetate, erythritol acetate and a trace of glycerol acetate were detected; and the molar proportions of the degradation products, glucose, mannose and erythritol, were calculated as $2 \cdot 4: 1 \cdot 0: 3 \cdot 5$.

\section{Methylation}

Purified SM-P was methylated four times using the method of Hakomori (1964). 2,3,4,6Tetra- $O$-methyl, 2,3,6-tri- $O$-methyl, and 2,4,6-tri- $O$-methyl hexoses were detected in the acid hydrolysate by thin-layer chromatography using benzene-acetone ( $\mathrm{I}: \mathrm{I}, \mathrm{v} / \mathrm{v})$ as solvent, and developing with the Molisch reagent (Dische, 1962). I,5-Di- $O$-acetyl-2,3,4,6-tetra- $O$ methyl hexitol, I,3,5-tri- $O$-acetyl-2,4,6-tri- $O$-methyl hexitol $(\mathrm{m} / e \mathrm{e3}, 45,87$, IOI, II 7, I29, I6r), and I,4,5-tri- $O$-acetyl-2,3,6-tri- $O$-methyl hexitol ( $m / e ~ 43,45,87,99$, Io I, I I 3 , I 7,233 ) were detected by gas-chromatographic mass spectrometry (Björndal, Lindberg \& Svensson, I967; Miyazaki \& Naoi, 1975) of the alditol acetates derived from methylated SM-P. The molar proportions in the hydrolysate of methylated SM-P are shown in Table 3.

\section{Analysis of oligosaccharides from controlled Smith-degradation products}

SM-P (6o mg) was oxidized for $6 \mathrm{~h}$ with sodium periodate using the above procedure, and reduced with sodium borohydride for $\mathrm{I} 8 \mathrm{~h}$ followed by dialysis. The oxidized and reduced 


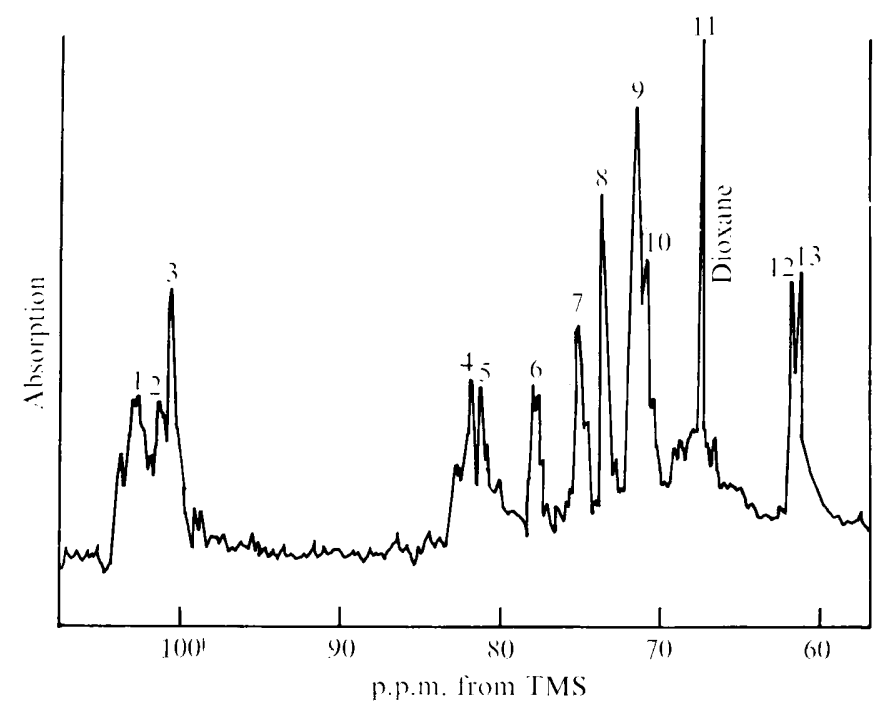

Fig. 3. The proton noise-decoupled ${ }^{13} \mathrm{C}$ Fourier transform n.m.r. spectrum of the polysaccharide at $25^{\circ} \mathrm{I} \mathrm{MHz}$, recorded under the following conditions: saturated solution at $80{ }^{\circ} \mathrm{C}$; solvent, $\mathrm{D}_{2} \mathrm{O}$; internal D lock; pulse width, $12 \mu \mathrm{s}$.

Peaks I to 3 were assigned to anomeric carbon atoms; peak 8 to $\operatorname{Glc}(\alpha) \mathrm{C}-3$; peak 9 to $\operatorname{Man}(\alpha)$ C-3, Glc $(\alpha)$ C-2 and Glc $(\alpha)$ C-5; peak io to $\operatorname{Glc}(\alpha)$ C-4 and $\operatorname{Man}(\alpha)$ C-4; peak I2 to Man $(\alpha)$ C-6; and peak I 3 to $\operatorname{Glc}(\alpha) \mathrm{C}-6$. For assignment of other peaks, see Results. Peak I I was the resonance from the standard dioxane $(67 \cdot 4$ p.p.m. downfield of TMS).

SM-P was hydrolysed with $0.25 \mathrm{M}$-sulphuric acid ( $15 \mathrm{ml}$ ) at $100^{\circ} \mathrm{C}$ for $2 \mathrm{~h}$; this gave at least five oligosaccharides which had $R_{\text {glucose }}$ values, i.e. $R$ values relative to the mobility of D-glucose, of $0.65,0.50,0.3 \mathrm{I}, 0.16$ and 0.03 . After air drying the paper chromatogram, the areas containing the two main fast-moving oligosaccharides were cut out and extracted with distilled water. The homogeneity of the two main oligosaccharides, O-I $\left(R_{\text {glucose }}, 0.65\right)$ and O-2 ( $R_{\text {glucose }}, 0.3 \mathrm{I}$ ), was examined by electrophoresis on Toyo Roshi glass fibre GH-Ioo in $0.042 \mathrm{M}$-borate buffer at $\mathrm{pH} 9.2\left(\mathrm{I} \mathrm{mA} \mathrm{cm}^{-1}\right)$. Each gave a single spot, detected by Molisch reagent, which moved to the cathode. Oligosaccharides O-I and O-2 were hydrolysed with $0.5 \mathrm{M}$-sulphuric acid at $100{ }^{\circ} \mathrm{C}$ for $5 \mathrm{~h}$, and then each hydrolysate was subjected to g.l.c. on ECNSS-M. The molar ratios of the component sugars, estimated from relative peak areas of the chromatogram, were: for O-I, 2 glucose: I mannose units; and for O-2, 2 glucose: 3 mannose units. Both O-I and O-2 showed absorption maxima in their i.r. spectra at $840 \mathrm{~cm}^{-1}$ characteristic of $\alpha$-glycosidic linkages. When $\mathrm{O}-\mathrm{I}$ and $\mathrm{O}-2$ were reduced with sodium borohydride, hydrolysed in $0.05 \mathrm{M}$-sulphuric acid and then acetylated, mannitol acetate was detected by g.l.c. in each hydrolysate.

Part of the oxidized and reduced SM-P was hydrolysed with $0.25 \mathrm{M}$-sulphuric acid at room temperature for $\mathrm{I} 8 \mathrm{~h}$, and produced two main oligosaccharides, O-I' $\left(R_{\mathrm{glucose}}, 0.52\right)$ and O-2' $\left(R_{\text {glucose }}, 0.076\right)$. These were purified by paper chromatography and further hydrolysed with $0.005 \mathrm{M}$-sulphuric acid for $2 \mathrm{~h}$ at $100{ }^{\circ} \mathrm{C}$. By this treatment, oligosaccharide $\mathrm{O}-\mathrm{I}^{\prime}$ produced glycerol, erythritol and oligosaccharide O-I $\left(R_{\text {glucosese }}, 0.65\right)$; and oligosaccharide O-2' produced erythritol, glucose, mannose, oligosaccharide O-I, and two other oligosaccharides having $R_{\text {glucose }}$ values of 0.23 and 0.06 . 


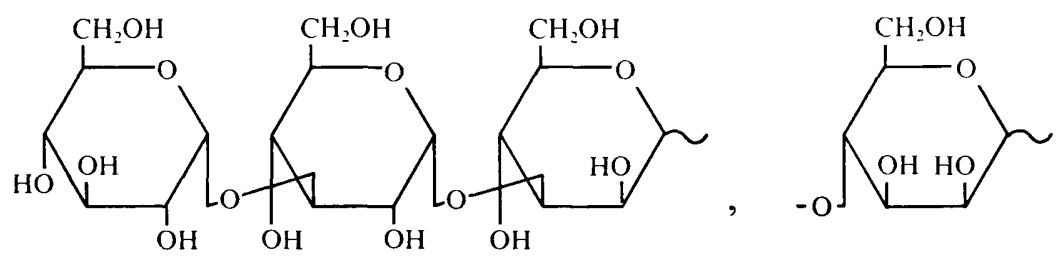

Oligosaccharide $\mathrm{O}-1$

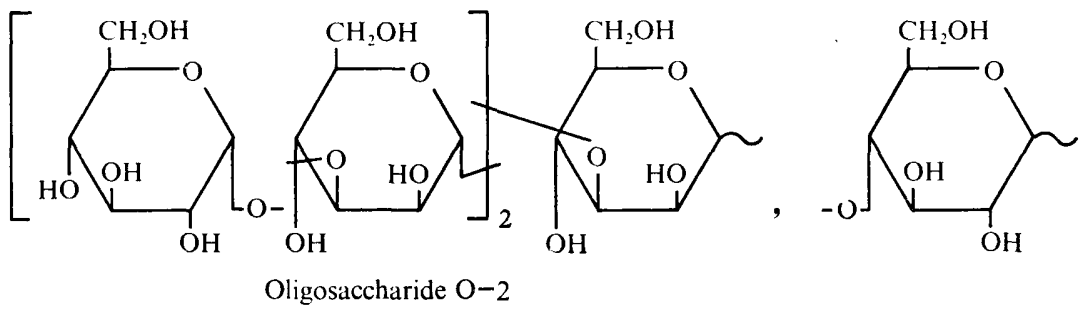

Fig. 4. The most probable sugar units in the polysaccharide SM-P.

\section{${ }^{13} \mathrm{C}$ Nuclear magnetic resonance spectrum}

The ${ }^{13} \mathrm{C}$ nuclear magnetic resonance spectrum of SM-P in $\mathrm{D}_{2} \mathrm{O}$ showed 12 resonances, at IоI·76, IOI·79, I00.0I $7,8 \mathrm{I} \cdot 475,80 \cdot 6,77 \cdot 59,74 \cdot 48,73 \cdot 03,7 \mathrm{I} \cdot 574,70 \cdot 895,62 \cdot 06$, and 6I·57 p.p.m. (Fig. 3). Those at IOI.79 and I00.0I7 p.p.m. were assigned to two anomeric carbons at $\alpha$-I,4- and $\alpha$-I,3-linkages of glucopyranosyl residues, respectively: the position of these resonances is in good agreement with those seen in spectra of nigerose and maltose (Usui et al., I973). Peak 5, at 80.6 p.p.m., and peak 6, at 77.59 p.p.m., were assigned to the C-3 and $\mathrm{C}-4$ resonances involved in the 3 -substituted and 4 -substituted glucopyranoses (Usui et al., 1973), respectively. Peaks 8, 9, I0, I2, and I3 were assigned to the non-substituted carbons of glucopyranose and mannopyranose by comparison with spectra of known $\alpha$-gluco- and $\alpha$-mannopyranoses (Johnson \& Jankowski, 1972; Gorin \& Mazurek, 1974). Peak I, at IOI'72 to IOI.76 p.p.m., may be assigned to anomeric carbons in $\alpha$-I,3- and $\alpha$-I,4linked mannopyranosyl residues, $\alpha$-I,3- and $\alpha$-I,4-linked glucopyranosyl-mannopyranosyl oligosaccharide moieties, and $\alpha-1,4$-linked mannopyranosyl oligosaccharide (Gorin, 1973). Peaks 4 and 7 may be assigned to C-3 and C-4 involved in $\alpha-\mathrm{I}, 3-$ and $\alpha$-I, 4 -linked glucopyranosyl and mannopyranosyl residues.

\section{CONCLUSIONS}

The purified extracellular polysaccharide of Streptomyces sp. strain FERM-PI I 85 contains glucose and mannose in the molar ratio $\mathrm{I} \cdot 87$ : $\mathrm{I}$. The presence of approximately equal proportions of I,3- and I,4-glycosidic linkages was shown by periodate oxidation, by methylation analysis and by ${ }^{13} \mathrm{C}$ nuclear magnetic resonance spectroscopy. Smith-type degradation gave oligomeric fragments that contained both glucose and mannose; thus both sugars are present in the same polymer. Methylation analysis showed that the polysaccharide is unbranched and has an average chain length of 46 hexapyranose residues. We conclude that the polysaccharide is a linear polymer that contains structures of the type shown in Fig. 4.

Glucomannans with a $\beta$-I,4-linked linear structure have been isolated from many plants belonging to the families Orchidaceae, Liliaceae and Iridaceae and also from wood 
hemicellulose (Aspinall, 1970) but glucomannans have not previously been isolated from streptomycetes; the mannoglucan from strain FERM-PII 85 differs by possessing a linear structure consisting of approximately equal amounts of $\alpha-1,4^{-}$and $\alpha-1,3$-linkages.

We thank Mrs O. Hayashi, K. Niwano, and K. Hata of Tokyo College of Pharmacy, and Ms Y. Miura of Kitasato University for technical assistance; and Mr K. Matsushita of the JEOL Co., Tokyo, for the ${ }^{13} \mathrm{C}$ n.m.r. measurements.

\section{REFERENCES}

Aspinall, G. O. (1970). Pectins, plant gums, and other plant polysaccharides. In The Carbohydrates, vol. 2B, pp. 530-53I. Edited by W. Pigman and D. Horton. New York: Academic.

Barker, S. A., BuURNe, F. J., NeEly, W. B. \& Whiffen, D. H. (I954). Infrared spectra of carbohydrates. V. Use of potassium bromide films. Chemistry and Industry I4I8.

BJÖRNDAL, H., LINDBERG, B. \& SVENSSON, S. (1967). Mass spectrometry of partially methylated alditol acetates. Carbohydrate Research 5, 433-440.

Dische, Z. (1962). General colour reactions. In Methods in Carbohydrate Chemistry, vol. I, pp. 478-48I. Edited by L. Whistler and M. L. Wolfrom. New York: Academic.

Dubois, M., Gilles, K. A., Hamilton, J. K., Rebers, P. A. \& Smith F. (1956). Colorimetric method for determination of sugars and related substances. Analytical Chemistry 28, 350-356.

Dubowski, K. M. (1962). An o-toluidine method for body-fluid glucose determination. Clinical Chemistry 8, $215-235$.

GoRIN, P. A. J. (1973). Rationalization of carbon-I3 magnetic resonance spectra of yeast mannans and structurally related oligosaccharides. Canadian Journal of Chemistry 51, 2375-2383.

GoriN, P. A. J. \& MAZUREK, M. (I974). Structure of a phosphonomannan, as determined by the effect of lanthanide ions on its carbon-1 3 magnetic resonance spectrum. Canadian Journal of Chemistry 52, 30703076.

HAKOMORI, S. (1964). A rapid permethylation of glycolipid, and polysaccharide catalysed by methylsulphinyl carbanion in dimethyl sulphoxide. Journal of the Biochemistry, Tokyo 55, 205-208.

HAY, G. W., LewIS, B. A. \& SMITH, F. (1965). Periodate oxidation of polysaccharides: general procedures. In Methods in Carbohydrate Chemistry, vol. 5, pp. 357-36I. Edited by R. L. Whistler. New York: Academic.

Hough, L., Jones, J. K. N. \& Wadman, W. H. (1950). Quantitative analysis of mixtures of sugars by the method of partition chromatography. V. Improved methods for the separation and detection of the sugars and their methylated derivatives on the paper chromatogram. Journal of the Chemical Society I702-1706.

JoHnSON, L. F. \& JANKowsKr, W. C. ( 1972). A collection of assigned, coded, and indexed spectra. In CarbonI3 NMR Spectra, pp. 197. Edited by L. F. Johnson and W. C. Jankowski. New York: WileyInterscience.

MIYAZAKI, T. \& NAOI, Y. (1975). Extracellular heteroglycan of Cladosporium tricoides. Studies on fungal polysaccharides. XVI. Chemical and Pharmaceutical Bulletin 23, 157-162.

Ōmura, S., Sato, T., Yamaguchi, K., Katagiri, M., Awaya, J., Iwai, Y. \& Hata, T. (I971). Studies on antibiotic O-2867, a new antibiotic. Journal of Antibiotics 24, 774-778.

Pridham, T. G. \& Tresner, H. D. (1974). Streptomycetaceae. In Bergey's Manual of Determinative Bacteriology, 8th edn, pp. 753. Edited by R. E. Buchanan and N. E. Gibbons. Baltimore: Williams \& Wilkins.

SAwARDeker, J. S., SloneCKer, J. H. \& JeAnes, A. (1965). Quantitative determination of monosaccharides and their acetates by gas liquid chromatography. Analytical Chemistry 37, 1602-1604.

ShirLing, E. B. \& GotTLIEB, D. (1966). Methods for characterization of Streptomyces species. International Journal of Systematic Bacteriology $16,313-340$.

Trevelyan, W. E., Procter, D. P. \& Harrison, J. S. (1950). Detection of sugars on paper chromatograms. Nature, London 166, 444-445.

Usui, T., Kobayashi, M., Yamaoka, N., Matsuda, K. \& Tuzimura, K. (I973). Structural determination of water-soluble dextran by C-I 3 and proton NMR spectroscopy. Tetrahedron Letters, 3397-3400.

WaKsman, S. A. (1953). Guide to the Classification and Identification of the Actinomycetes and their Antibiotics, pp. I-I 62. Baltimore: Williams \& Wilkins.

WhisTler, R. L. \& HICKSON, J. L. (I954). Maltotetraose and crystalline pentadecaacetyl maltotetraitol. Journal of the American Chemical Society 76, 1671-1673. 